\title{
Longitudinal Patterns of Material Hardship Among US Families
}

\author{
Margaret M. C. Thomas ${ }^{1}$ (D)
}

Accepted: 3 February 2022 / Published online: 3 March 2022

(c) The Author(s) 2022

\begin{abstract}
Material hardship has emerged as a direct measure of deprivation in the United States and an important complement to income poverty, providing different evidence about the ways in which deprivation may affect wellbeing. This study addresses gaps in our knowledge about deprivation as the first to examine patterns of material hardship over time. Using data from the Fragile Families and Child Well-Being Study, this study examined five material hardship types (food, housing, medical, utility, and bill-paying) experienced at five timepoints over 15 years. Employing latent class analysis and latent transition analysis, this study identified six longitudinal patterns of material hardship experience, characterized by trajectories of stability or movement and relative severity of material hardship experience over time. These findings improve our conceptual understanding of deprivation and move us towards understanding the impacts of material hardship on wellbeing and identifying policy approaches to prevent deprivation or mitigate negative consequences.
\end{abstract}

Keywords Material hardship $\cdot$ Poverty $\cdot$ Economic wellbeing $\cdot$ Latent class analysis

\section{Introduction}

In the past 30 years, material hardship has emerged as a direct measure of the fundamental problem of deprivation (the experience of want in terms of basic needs) in the United States (Beverly, 2001; Heflin et al., 2009; Mayer \& Jencks, 1989). This is in contrast to longstanding practices in both policymaking and research, which have tended to favor income poverty as a proximate, but still indirect, measure of deprivation. Income poverty measures a family's monetary resources against an established benchmark such as the US federal poverty level (FPL), which represents the estimated minimum income necessary to pay for basic needs. In contrast, material hardship measures a family's actual experiences of being unable to pay for certain basic needs. For instance, the present study assessed families' experiences of needing to rely on free food or meals due to lack of money; losing housing or experiencing homelessness; being unable to access needed medical care; having

Margaret M. C. Thomas

thomas@luskin.ucla.edu

1 Department of Social Welfare, Luskin School of Public Affairs, University of California Los Angeles, 3250 Public Affairs Building, Los Angeles, CA 90095, USA 
electricity, gas, oil, or telephone utilities shut off; and being unable to pay rent, mortgage, or utility bills every month. Thus, unlike income poverty, which refers to likely experiences of deprivation, measures of material hardship assess real gaps in meeting those basic needs due to insufficient monetary resources. Measures of material hardship accommodate different combinations, costs, and variability in essential needs among families.

Although material hardship and income poverty are associated with one another, multiple assessments of their relationship have demonstrated the two constructs are markedly different (Dhongde \& Haveman, 2015; Gershoff et al., 2007; Short, 2005; Sullivan et al., 2008). Indeed, the relatively weak correlations between material hardship and income poverty (correlations in the range of .18-.40 for both individual hardships and index measures) are strong evidence that income poverty does not universally predict experiences of deprivation (Mayer \& Jencks, 1989; Rodems \& Shaefer, 2020; Schenck-Fontaine \& Panico, 2019; Short, 2005; Sullivan et al., 2008). In directly measuring families' inability to meet basic needs, material hardship is an important complement to income poverty. Although research on material hardship is increasing, there are substantial gaps in current research, particularly around the measurement and conceptualization of material hardship, with implications for its incorporation in empirical work.

This study provides the first evidence about coherent patterns of material hardship over time, examining and differentiating common and meaningful trajectories which describe families' movements between specific material hardship experiences over a period of nearly 15 years. As material hardship gains prominence as a valuable and meaningful measure of need (e.g., Karpman et al., 2018a, 2018b; McKernan et al., 2018; Payton Scally \& Gonzalez, 2018), this novel empirical classification supports an understanding of material hardship which is nuanced and comprehensive while remaining concise and measurable. This combination of features is essential to ensuring measures of material hardship describe the complex experience of deprivation while providing sufficiently succinct classifications to be useful in understanding families' experiences and in developing and analyzing policy.

\section{Background}

\subsection{Measuring Material Hardship}

Existing research has attended with care to articulating, testing, and refining definitions and some measures of material hardship, although work in this area has been limited to a handful of previous studies (Beverly, 2001; Carle et al., 2009; Heflin et al., 2009; Mayer \& Jencks, 1989; Short, 2005). Researchers have conceptualized material hardship as the inability to meet basic material needs, measured in a variety of different ways over different studies (Carle et al., 2009; Gershoff et al., 2007; Heflin et al., 2009; Mayer \& Jencks, 1989). Most prior research has considered multiple dimensions of hardship, such as food, medical, and bill-paying; however, there is great variation in whether those dimensions were considered as discrete experiences of hardship (Carle et al., 2009; Heflin, 2006; Heflin et al., 2009; Karpman et al., 2018b; Neckerman et al., 2016; Nepomnyaschy \& Garfinkel, 2011; Zilanawala \& Pilkauskas, 2012); items in a summative index, indicating magnitude of hardship (Karpman et al., 2018b; Mayer \& Jencks, 1989; Nepomnyaschy \& Garfinkel, 2011); or as contributors to a dichotomous indicator for any hardship experience (Karpman et al., 2018b; Neckerman et al., 2016; Zilanawala \& Pilkauskas, 2012). 
Only a small number of prior studies have specifically assessed the goodness-of-fit of material hardship measures, using factor analysis to identify distinct types of hardship, such as housing and food hardship (Carle et al., 2009; Heflin et al., 2009). Such work highlights the importance of examining discrete domains of material hardship as substantively and qualitatively different. Yet, investigating single dimensions of hardship risks missing information about the magnitude of hardship experiences, which summative measures can provide (Karpman et al., 2018b; Nepomnyaschy \& Garfinkel, 2011). However, summative measures are also limited in that that they assume that hardship exists along an orderly continuum and that each type of hardship contributing to the scale has equal weight. Perhaps most significantly, in addition to these measurement limitations, there has been very little previous longitudinal work examining how people experience material hardship over time (Heflin, 2006, 2017) and none exploring whether it is possible to develop a coherent, longitudinal conceptualization of material hardship. In sum, while researchers have conceptualized material hardship as multifaceted (Heflin et al., 2009; Mayer \& Jencks, 1989; Neckerman et al., 2016), and it is possible that families experience distinct patterns of hardship over time, previous work has mostly not attempted to investigate these important issues. As discussed below, the present study begins to address these measurement challenges and limitations. Developing a multifaceted and longitudinal conceptualization of material hardship stands to improve our understanding of hardship as it is actually experienced in people's lives. Of particular importance, understanding how specific types of hardship occur concurrently and longitudinally opens the door to more targeted policy and program responses to mitigate or prevent detrimental experiences of hardship.

\subsection{Correlates of Material Hardship}

Drawing on the various measures described above, a number of prior studies have assessed material hardship as a dependent variable, predicted by social positioning (Heflin, 2017; Karpman et al., 2018a, 2018b), non-resident father involvement (Nepomnyaschy \& Garfinkel, 2011), family instability (Heflin, 2016), Supplemental Nutrition Assistance Program (SNAP) participation (Shaefer \& Gutierrez, 2013), and broadly-defined public assistance receipt (McKernan et al., 2018; Wu \& Eamon, 2010). Consistent with economic wellbeing research broadly, these studies have demonstrated increased likelihood of material hardships among families of Black or Latinx race and ethnicity, those headed by single-mothers, those including at least one member with a disability, those with children, and those eligible for but not receiving public assistance.

Research has also begun to examine material hardship as an independent variable. Findings from this work point generally to negative implications of material hardship exposure for central elements of wellbeing, including physical health, cognitive development, behavioral and mental health, and educational attainment (Chaudry \& Wimer, 2016; Neckerman et al., 2016; Pilkauskas et al., 2012; Yoo et al., 2009; Zilanawala \& Pilkauskas, 2012). For instance, Zilanawala and Pilkauskas (2012) examined material hardship as a predictor of children's socioemotional behavior and found that hardship predicted more internalizing and externalizing behavior problems. Yoo and colleagues (2009) found material hardship, and most strongly food hardship, to be predictive of worse parent-reported health status among children. Heflin and Iceland (2009) found five discrete material hardships each to be significant predictors of maternal depression. Interestingly, McCarthy and colleagues (2016) found that material hardship was a stronger predictor of self-reported mental health and depression than was income poverty. 
Some studies have attended specifically to this distinction between material hardship and income poverty and have tested whether material hardship mediates the relationship between income poverty and other outcomes (Chaudry \& Wimer, 2016; Gershoff et al., 2007). However, much extant literature makes the case that while associated, income poverty and material hardship are distinct from one another (Beverly, 2001; Neckerman et al., 2016; Short, 2005; Sullivan et al., 2008). Using the best available datasets, prior research has tested multiple measures of income poverty and material hardship against one another and found they are far from perfectly correlated (Beverly, 2001; Neckerman et al., 2016; Rodems \& Shaefer, 2020; Short, 2005; Sullivan et al., 2008). Further, material hardship has been found specifically to predict poor mental health outcomes more accurately than and independently of income (McCarthy et al., 2016; Sullivan et al., 2008) and has been found to better explain children's health status than does socioeconomic status (SES; Yoo et al., 2009).

Additionally, while material hardship decreases somewhat as income increases, it does so at a slower and distinct rate (Sullivan et al., 2008). A number of studies have demonstrated that there are many people who experience material hardship but have income well above the poverty threshold (Karpman et al., 2018b; Neckerman et al., 2016; Rodems \& Shaefer, 2020; Short, 2005; Sullivan et al., 2008). For instance, Karpman et al. (2018b) examined material hardship experience in a 2017 US national sample of adults ages 18-64, identifying sizable rates among those with income above the FPL, including 61\% of those with income between 100 and $200 \%$ of FPL, 44\% of those with income between 200 and $400 \%$ of FPL, and $18 \%$ of those with income at $400 \%$ or more of FPL. These trends demonstrate a broad, negative relationship between income and material hardship but also emphasize the notably different groups of people who experience income poverty and material hardship. While the current study does not test explanations for these differences, prior work suggests a range of reasons that may explain the different distributions of income poverty and material hardship, including well-established shortcomings of the income poverty measure and differences in economic need related to individual circumstances (health conditions, cultural values, family composition, assets), contextual factors (cost of living, availability of resources), and individual skills and capacities (mental health, financial literacy) (e.g., Bradshaw \& Finch, 2003; Heflin, 2017; Karpman et al., 2018a, 2018b; Zilanawala \& Pilkauskas, 2012).

\subsection{Current Study}

The present study aimed to expand our understanding of material hardship as an essential social indicator, particularly by considering experiences of material hardship over time. Recognizing that experiences of material hardship do not happen in a vacuum and may co-occur (Karpman et al., 2018b), this study developed a data-driven classification of concurrent material hardship experiences in order to identify longitudinal patterns of material hardship. These patterns represent the first longitudinal conceptualizations of material hardship and provide insight into the trajectories through different groupings of material hardship which families experience. Understanding such patterns is of particular interest in light of existing research on income poverty, which indicates the urgency of assessing the timing and duration of deprivation in relationship to wellbeing, particularly for children (Brooks-Gunn \& Duncan, 1997; Duncan et al., 1994; Ratcliffe \& Mckernan, 2010). While evidence on the consequences of material hardship in the US is nascent, research on income poverty suggests the consequences of deprivation are likely to differ depending 
on whether it is transitory or chronic and inconsistent or stable. Identifying longitudinal patterns of material hardship is an essential step toward understanding these dynamics and their implications for wellbeing.

These potential consequences for child wellbeing motivated this study's attention to families with children but should not be interpreted as suggesting that material hardship among other populations, including childless adults, whose hardship is frequently deprioritized in the context of social welfare responses, is less worthy of investigation. While the present study relies on a sample of families with children, as a novel contribution to the literature, it offers a starting point for examining longitudinal patterns of material hardship more generally. Beyond identifying such patterns, the present study also examined the social positioning characteristics of families that were correlated with experiences of specific material hardship patterns (by social positioning, I mean those demographic, educational, occupational, and economic factors that shape individuals' positions in society). In so far as we expect that families are likely to face different consequences based on the dynamics of their material hardship experience, understanding those characteristics which are correlated with pattern membership is vital to identifying families who are at greatest risk of material hardship and to developing policies and programs which can be directed accordingly.

To address these aims, this study answered two sequential research questions. First, what are the most common patterns of material hardship experienced by families over time? And second, which family social positioning characteristics are correlated with membership in specific longitudinal material hardship patterns?

\section{Methods}

\subsection{Data}

This study used data from all six of the current waves of the public version of the Fragile Families and Child Well-Being Study (FFCWS). The FFCWS is an ongoing longitudinal birth cohort study, which gathers information about a baseline sample of approximately 4900 births between 1998 and 2000 in 20 large US cities (Reichman et al., 2001). Following the baseline interviews at the focal child's birth, data have been collected when the child was approximately 1, 3, 5, 9, and 15 years old. In the latest, 15-year wave, the sample size is approximately 3600 families, with approximately 1300 families having attrited from the sample since the baseline interviews (Princeton University, 2017). The FFCWS was designed to oversample families facing precarious circumstances, for which non-marital births may be a proxy, and so the FFCWS sample included approximately $75 \%$ unmarried parents and 25\% married parents. Thus, this sample of primarily unmarried parents is also a sample of those families which are more likely to experience limited resources, lower socioeconomic status, marginalized race and ethnicity, and likely, greater material hardship (McLanahan et al., 1999; Reichman et al., 2001). The FFCWS data provide invaluable information representative of a significant population of hard-to-reach families who are particularly vulnerable to some harmful experiences, such as deprivation, and when weighted, the data are representative of all US cities with populations of 200,000 or more as of 1998.

Moreover, FFCWS is the only US, national-level dataset with repeated measures of numerous types of material hardship. Other data sources include cross-sectional measures 
of hardship (e.g., prior Survey of Income and Program Participation (SIPP) panels ${ }^{1}$; Ouellette et al., 2004); capture only a subset of material hardship types (e.g., the redesigned SIPP; National Academies of Sciences, Engineering, and Medicine, 2018; Panel Study of Income Dynamics (PSID); Survey Research Center, Institute for Social Research, University of Michigan, 2021); reflect particular populations, such as single-mother Temporary Assistance for Needy Families (TANF)-recipient households (e.g., Women's Employment Study; Tolman et al., 2018); or sample specific localities (e.g., New York City Longitudinal Study of Wellbeing; Center on Poverty \& Social Policy, 2019). No other data source provides consistent and repeated measures of multiple types of material hardship, allowing for the longitudinal analyses undertaken in this study. In addition, the FFCWS data include comprehensive information about parents' identities, relationships, and social and economic resources, which are key variables in understanding the characteristics of families experiencing material hardship.

\subsection{Sample}

The present study uses a sample of 2772 families, representing all those families in which the focal child resided primarily with their biological mother and/or father and in which the custodial parent had complete data on all material hardship questions asked consistently across all post-baseline study waves. Given the study's primary reliance on data-driven, latent material hardship constructs, I chose not to impute missing material hardship data, consistent with one prior study examining material hardship and child wellbeing using the FFCWS data (Zilanawala \& Pilkauskas, 2012). It seems likely that material hardship data may have been missing not at random, which is to say, unmeasured factors related to both the values of missing material hardship data and the decision not to answer hardship questions could create unknown bias in imputing missing hardship data (Nicoletti et al., 2011). Because the present study's analysis was exploratory and aimed at understanding the basic definition and meaning of concurrent and longitudinal material hardship experiences, I chose to use a complete case sample, which may have biased the study sample toward greater advantage but did not introduce the bias which accompanies any missing data approach (Stavseth et al., 2019; White \& Carlin, 2010). Based on previous research that has found material hardship among families with incomes well above the federal income poverty thresholds (Rodems \& Shaefer (2020); Karpman et al., 2018b; Neckerman et al., 2016), the sample specifically included families along the full distribution of income present in the data.

Table 1 provides descriptive statistics about the sample families. ${ }^{2}$ A comparison of families in the analytic sample with excluded families (see Appendix 1) revealed a number of statistically significant but mainly small-magnitude differences across social positioning

\footnotetext{
1 An exception to these data limitations is the two consecutive waves of the 2008 SIPP in which material hardship data were collected. These repeated measures have been examined (e.g., Heflin, 2017) but still represent only two time points compared to the five time points at which the FFCWS provides data.

2 FFCWS includes survey weights, which can be used to make the data representative of all births in large US cities in the study period (populations of 200,000+ in 1994). I did not apply the weights to the descriptive statistics because I elected not to use the weights in the primary analyses, as a drawback to their use is a reduction in sample size because the weights do not utilize all cases in the FFCWS (Carlson, 2008). Additionally, my multivariate models account for differences in those key family characteristics which are incorporated in the survey weights, which does not replicate the weighting mechanism but does account for measurable family-level differences.
} 
Table 1 Sample descriptive statistics

\begin{tabular}{|c|c|c|}
\hline Characteristic ${ }^{\mathrm{a}, \mathrm{b}}$ & Proportion & SE \\
\hline Child sex (male) & 0.518 & 0.518 \\
\hline Child age at 1 -year wave (months) & 14.918 & 14.918 \\
\hline Child born at low birth weight (yes) & 0.093 & 0.093 \\
\hline Poverty ratio, continuous & 2.294 & 2.294 \\
\hline \multicolumn{3}{|l|}{ Poverty ratio, categorical } \\
\hline$<50 \% \mathrm{FPL}$ & 0.168 & 0.168 \\
\hline $50-99 \%$ FPL & 0.166 & 0.166 \\
\hline $100-199 \%$ FPL & 0.261 & 0.261 \\
\hline 200-299\% FPL & 0.160 & 0.160 \\
\hline $300 \%+\mathrm{FPL}$ & 0.245 & 0.245 \\
\hline Mother age (years) & 25.209 & 25.209 \\
\hline \multicolumn{3}{|l|}{ Mother race and ethnicity } \\
\hline White, non-Latinx & 0.233 & 0.233 \\
\hline Black, non-Latinx & 0.501 & 0.501 \\
\hline Any race, Latinx & 0.232 & 0.232 \\
\hline Other race, non-Latinx & 0.034 & 0.034 \\
\hline Mother not US-born & 0.122 & 0.122 \\
\hline \multicolumn{3}{|l|}{ Mother education level } \\
\hline Less than high school & 0.300 & 0.300 \\
\hline High school or equivalent & 0.320 & 0.320 \\
\hline Some college or technical school & 0.261 & 0.261 \\
\hline College or advanced degree & 0.119 & 0.119 \\
\hline \multicolumn{3}{|l|}{ Mother housing status } \\
\hline Own & 0.371 & 0.371 \\
\hline Rent, no government assistance & 0.456 & 0.456 \\
\hline Rent, with government assistance & 0.061 & 0.061 \\
\hline Public housing & 0.108 & 0.108 \\
\hline Other & 0.005 & 0.005 \\
\hline \multicolumn{3}{|l|}{ Mother relationship to biological father } \\
\hline Married & 0.252 & 0.252 \\
\hline Cohabitating & 0.355 & 0.355 \\
\hline Other & 0.393 & 0.393 \\
\hline Mother total number of children & 2.100 & 2.100 \\
\hline Mother worked in year prior to child's birth & 0.154 & 0.154 \\
\hline Mother lived with both own bio parents at age 15 & 0.581 & 0.581 \\
\hline $\begin{array}{l}\text { Mother poor health status } \\
\text { (good/fair/poor vs. very good/excellent) }\end{array}$ & 0.325 & 0.325 \\
\hline Mother met depression criteria at 1-year wave & 0.157 & 0.157 \\
\hline
\end{tabular}

${ }^{\mathrm{a}}$ Measured at baseline unless otherwise noted

${ }^{\mathrm{b}}$ Waves correspond to years as follows: baseline, 1998-2000; 1-year wave, 1999-2001

characteristics. Overall, these differences suggest the analytic sample represented families with more socioeconomic advantage, reflected in higher income and educational attainment and lower public assistance receipt, and disproportionately included more 
non-Latinx-identified families. As is common in survey data, those families with the most disadvantage were more likely to attrite from the sample, as disadvantage can result in instability and difficulty maintaining contact with families for follow up surveys (Hardy, 2014; Pilkauskas et al., 2012; Stone \& Rose, 2011). As such, the findings of this study are likely to represent a lower-bound estimate of the prevalence and severity of material hardship, as those families excluded from the sample were more disadvantaged.

\subsection{Measures}

\subsubsection{Material Hardship}

Material hardship is measured in every wave of the FFCWS data except for the baseline. Questions ask parent respondents to report on material hardships experienced in the past 12 months. At each wave, all of the material hardship questions are prefaced with the following contextualizing statement: "We are also interested in some of the problems that families face making ends meet. In the past 12 months, did you do any of the following because there wasn't enough money?" Across all waves, nine material hardship questions are asked consistently and form the basis of the measures of material hardship used in this study, consistent with prior research (Heflin \& Iceland, 2009; Heflin et al., 2009; Nepomnyaschy \& Garfinkel, 2011; Pilkauskas et al., 2012; Zilanawala \& Pilkauskas, 2012).

Most material hardship research has examined discrete categories of hardship composed of one or more indicators (e.g., Heflin, 2017; Heflin \& Iceland, 2009), although some research has then further aggregated categories into a single index (Nepomnyaschy \& Garfinkel, 2011; Pilkauskas et al., 2012). This study measured material hardship as discrete hardships in the areas of food, housing, medical care, utilities, and essential bill-paying, in keeping with prior research that has demonstrated meaningful differences among these specific hardship types (Heflin et al., 2009). The present study's measures of material hardship were also consistent with prior research on material hardship using the FFCWS (Pilkauskas et al., 2012; Zilanawala \& Pilkauskas, 2012). These measures are drawn from FFCWS questionnaires and summarized in Table 2.

Figure 1 demonstrates the prevalence of each of the five discrete types of material hardship at each wave of the data. Across all waves, bill-paying hardship was consistently most common, while medical hardship was least common. All differences in the prevalence rates for each type of hardship within a given wave were statistically significant $(p<.05)$, with the exception of statistically comparable rates of food and housing hardships in the 3-year and 5-year waves. Differences in the prevalence of each material hardship type over time were more varied. For food, housing, and bill-paying hardships, trajectories of increasing (food and bill-paying) or decreasing (housing) hardship over time were evident in statistically comparable prevalence rates between many adjacent waves but significantly different $(\mathrm{p}<.05)$ rates in early and late waves. In contrast, medical hardship and utility hardship demonstrated largely stable prevalence rates across time and therefore reflected more statistically comparable rates between all waves.

\subsubsection{Family Characteristics}

A comprehensive set of variables reflecting families' social positioning characteristics were included in this study. These characteristics were drawn from mothers' reports at the baseline interviews and reflected prior research identifying important demographic correlates 


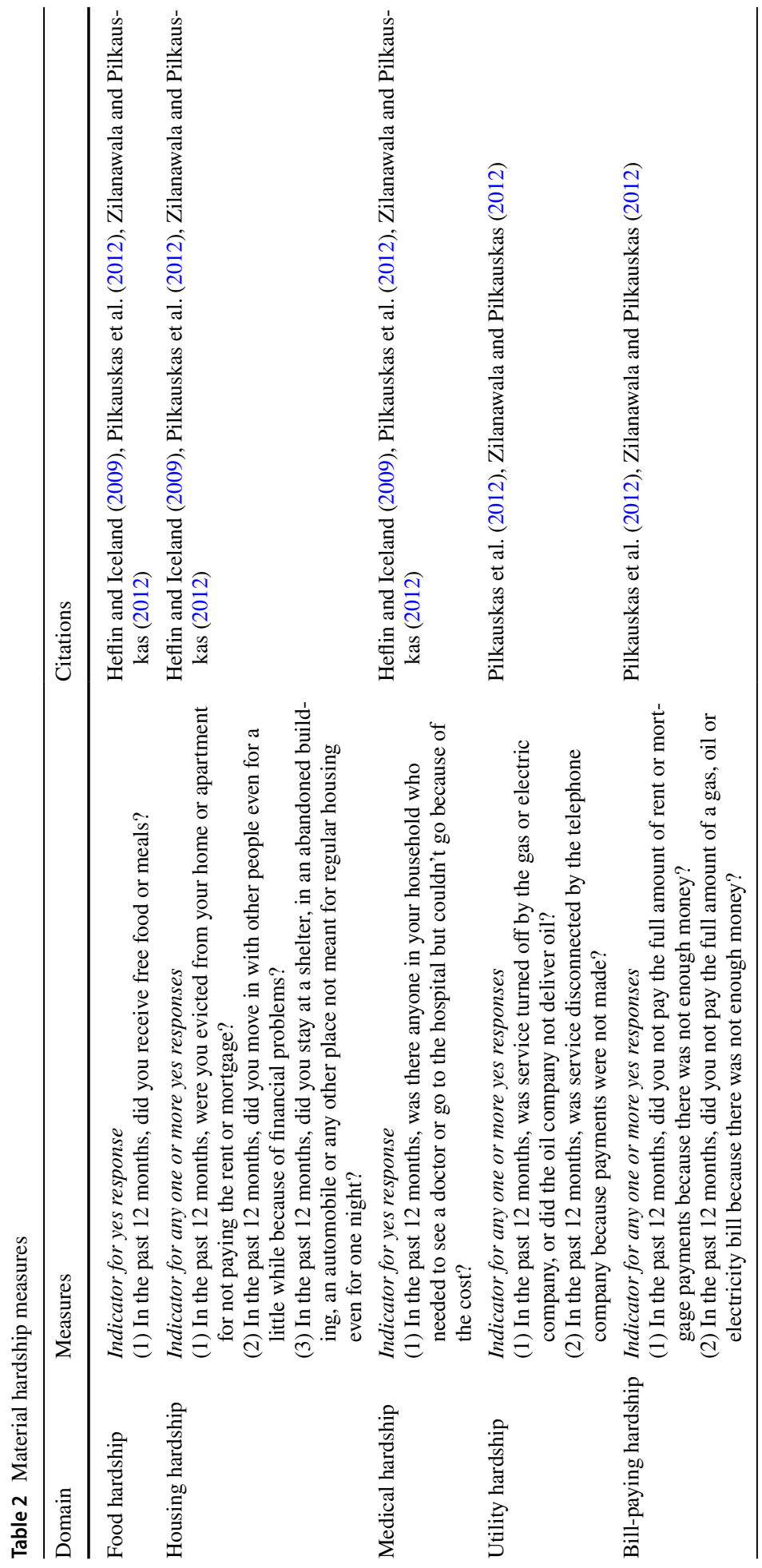




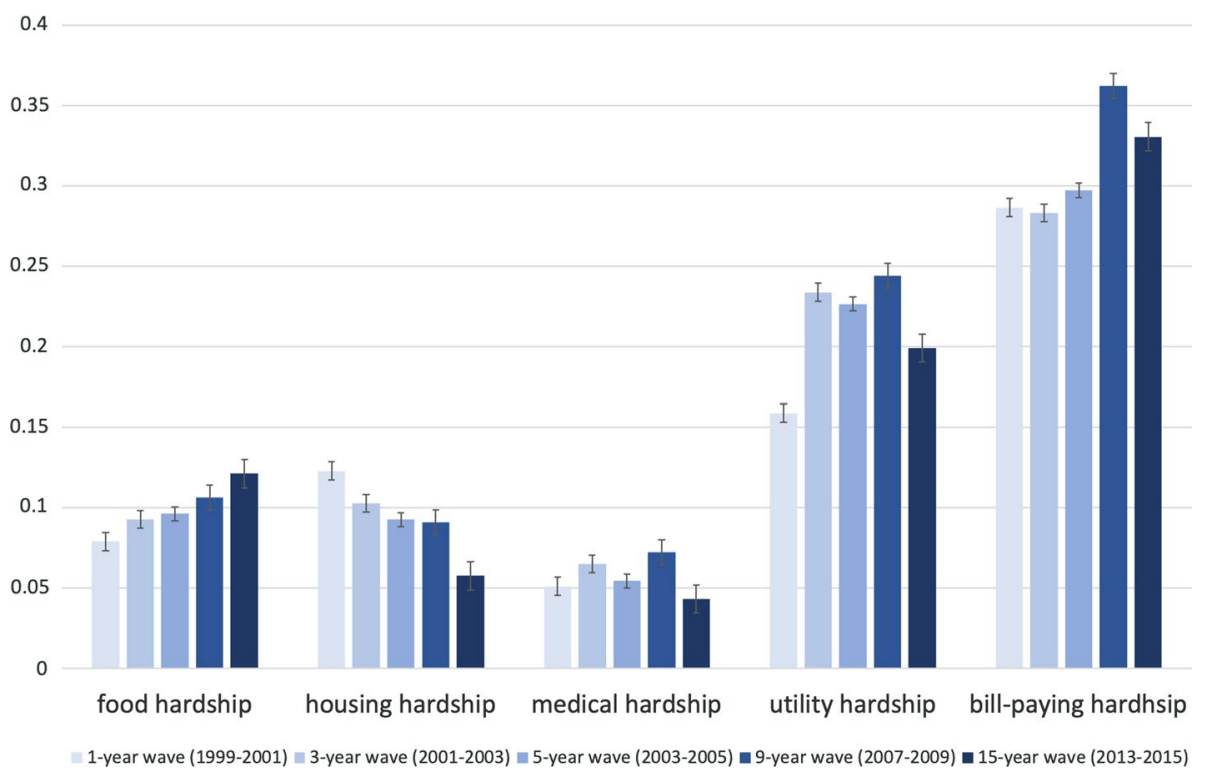

Fig. 1 Prevalence of material hardships over time

of material hardship (Heflin, 2017; Karpman et al., 2018b; Wimer et al., 2014). Measures included mother income-to-poverty ratio, mother age, mother race and ethnic group membership, whether mother was born in the US, mother education level, mother housing status, mother relationship to the child's biological father, mother number of children, whether mother worked during the year prior to the focal child's birth, whether mother lived with both of her own parents at age 15 (an indicator of extended family resources and SES), an indicator measure of mother poor health status, whether mother met criteria for depression on a standardized scale, child sex, whether child was born at low birth weight, and child's age at the 1-year interview. This child age measure was used because all children were within days of birth at the baseline interview, but 1-year interviews captured children ranging in age from 9 to 30 months.

\subsection{Analysis}

To investigate longitudinal patterns of material hardship, this study used the complementary techniques of latent class analysis (LCA) and latent transition analysis (LTA), using Mplus statistical software (Muthén \& Muthén, 2019).

\subsubsection{Latent Class Analysis}

LCA examines sets of measured characteristics that are hypothesized to collectively approximate an unmeasured, or latent, variable (Lanza \& Rhoades, 2013). LTA extends this technique to identify transitions over time in observations' values on this latent construct (Lanza \& Collins, 2008). The present study first identified a latent material hardship class variable, which was approximated by combinations of one or more of the observed types of material hardship. In the context of this study, a latent material 
hardship measure is a single hardship constructed which accounts for different combinations of hardship experiences, capturing both the quantity and specific qualities of hardship which are common to families' experiences. A latent measure of this sort offers an alternative way to conceptualize the concurrent experiences of different forms of hardship, preserving the substantive differences between forms of hardship which an index measure obscures but also accounting for intensity or quantity of hardship, which single-domain measures miss. The utility of LCA rests on the assumption that it is unlikely that every individual combination of values of the indicator variables represents a distinct and meaningful experience but rather that a smaller subset of common combinations may emerge, reflecting real groups of observations in identifiable and distinct classes (Collins \& Lanza, 2010; Lanza \& Rhoades, 2013).

Identifying the number of classes which best captures the variation in class membership within a dataset requires estimating a series of LCA models with different numbers of classes and comparing these models using established model fit statistics (Collins \& Lanza, 2010; Ryoo et al., 2018). This study considered separate LCA models with different numbers of classes (3 through 5 ) within each wave and determined a 3-class analytic model in each wave was the best fit to the data, based on the BIC model fit statistic (see Appendix 2). In keeping with prior research, the present study assumed a priori that more meaningful information would be available by examining multiple classes rather than the simple dichotomy represented by a 2-solution model (Lanza \& Rhoades, 2013; Nylund, 2007).

Establishing the form of the LCA model, in this case a 3-class model at each wave, allows for the identification of the relative frequency of each of the three latent classes (class probability parameters) and the probability an individual in each of the given latent classes endorses each of the five material hardship types (item probability parameters). I used the class and item probability parameters to estimate posterior probabilities of latent class membership for each observation, calculating the likelihood an individual belonged to a given latent class based on the prevalence of that class and the individual's experience of the five discrete types of material hardship. In a process called modal class assignment, I then assigned each observation to the latent class for which its posterior probability was highest (Nylund, 2007; Ryoo et al., 2018; Schuler et al., 2014). An important limitation to this approach is that such assignment is by definition probabilistic. I assigned each observation membership in a single class despite non-zero probability that some observations could be assigned to other class. This uncertainty in class assignment introduces some measurement error into these analyses, which likely reduces the precision of the multivariate regression model estimates.

Having identified the number of latent classes and membership of individuals in those latent classes at each of the five waves of data (years 1, 3, 5, 9, and 15), I then examined those cross-sectional models to understand whether the three latent material hardship classes which appeared at each wave were conceptually consistent. While there were some minor differences, each set of three material hardship classes largely represented the same three categories, which I labeled based on the specific types of hardship and number of hardships families commonly experienced, described in greater detail in the Results section. Further, I used model fit statistics to conduct a formal test of the assumption of measurement invariance, which if it holds, indicates the item probability parameters (i.e., the prevalence of a given material hardship type within each of the three material hardship classes) should be held constant across time (Lanza \& Collins, 2008; Nylund, 2007; Ryoo et al., 2018). Specifically, examining the BIC model fit statistic for a 3-solution model which assumed measurement invariance, and for one which did not, indicated that the 
measurement invariant model was a better fit (see Appendix 2). That is, both visual checks and data fit statistics indicated that the same three classes were present at each wave.

\subsubsection{Latent Transition Analysis}

The second phase of analysis assigned families to longitudinal material hardship patterns signified by sequences of material hardship class values. I used the 3-solution, measurement invariant LTA model described above to identify and assign families to sequences of material hardship classes across the 1-15-year waves (Lanza \& Collins, 2008). This model produced class probability parameters at each time point as well as a matrix of transition probabilities, which estimate the likelihood of transition to each of the three material hardship classes at a given time point, conditioned on class membership at the previous time point. Approximately $90 \%$ of families' experiences were described by 36 of the $243\left(3^{5}\right)$ possible sequences of transitions.

Having identified these most common sequences, I examined the qualitative patterns those sequences represented and further grouped all sequences into six conceptually meaningful patterns of material hardship experience. To assign each family to one of the six longitudinal patterns, I utilized posterior probabilities of class membership at each point in time and assigned each observation a value for longitudinal pattern membership based on the six groups of sequences described above (Collins \& Lanza, 2010; Nylund, 2007). One measure of the success of LCA and LTA models in clearly distinguishing groups is a model-specific measure of entropy. A model's entropy indicates how definitively it has separated latent classes. Methodological literature is explicit that there is not an established cutoff for acceptable entropy while also suggesting that entropy below .6 is likely indicative of a poorly fit model and entropy above .8 is likely indicative of a very well-fit model (Weller et al., 2020). The final LTA model I used in this study demonstrated entropy of .72 , which while not an exceptional level of discrimination between classes suggests sufficiently clear distinctions between class memberships for meaningful interpretation.

\subsubsection{Correlates of Membership in Material Hardship Patterns}

Building on the identification of these longitudinal patterns of material hardship, the final phase of analysis examined families' social positioning characteristics as predictors of pattern membership. Specifically, I used multinomial logistic regression to predict material hardship pattern over the 1-15-year waves from baseline social positioning characteristics.

\section{Results}

\subsection{Identify Material Hardship Patterns}

The results of the LCA analysis identified three meaningful classes of material hardship experience that - as noted above-were consistent across wave. The classes are defined empirically by the relative frequencies of each of the five discrete types of material hardship, which are summarized in Fig. 2. The three latent material hardship classes which emerged from this analysis can be summarized as follows: (1) a Limited Material Hardship class characterized by low probability of bill-paying hardship and very low probability of all other hardships; (2) a Moderate Material Hardship class characterized by high 
0.9

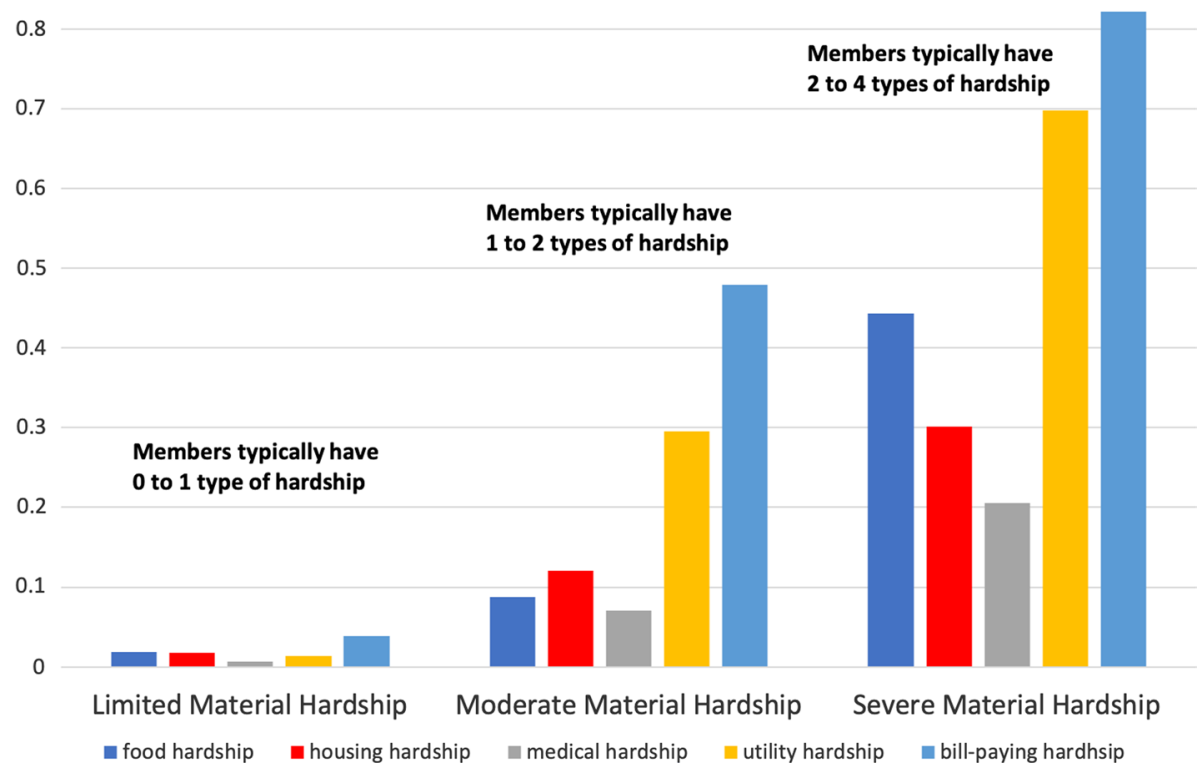

Fig. 2 Material hardship item probability parameters by class

probability of bill-paying hardship, moderate probability of utility hardship, and lower probability of housing, food, and medical hardships; and (3) a Severe Material Hardship class characterized by very high probability of bill-paying and utility hardships, high probability of food hardship, and moderate probability of housing and medical hardships. I present these specific item probability parameters derived from the longitudinal (LTA) model, which held these parameters constant across time, in Fig. 2.

Because the item probability parameters were constant across waves, they provided a consistent structure to each of the three material hardship classes-e.g., independent of wave, about half of all families in the moderate material hardship group experienced billpaying hardship, and about a third experienced utility hardship. However, the relative frequencies of the three latent classes varied across time. Figure 3 presents the prevalence of the three material hardship classes at each point in time. While the order of prevalence remained the same-limited material hardship was always most common, followed by moderate and then severe - the classes showed somewhat different trends. The prevalence of limited material hardship fluctuated but mainly decreased before spiking to its highest prevalence rate at the final wave. The prevalence of moderate material hardship fluctuated throughout but dropped notably at the final wave. In contrast, severe material hardship prevalence increased gradually over time.

To identify longitudinal patterns of material hardship, I drew on the cross-sectional material hardship classes described here in combination with families' predicted probabilities of transition between those classes across the 1-15-year timeframe. Table 3 presents probabilities of transition from a given class to each other class between each time point.

Based on the prevalence of each class (Fig. 3), and the between-class transition probabilities (Table 3), I identified, labeled, and described the six most common longitudinal patterns of material hardship. As described in the Analysis section, those patterns were 
0.7

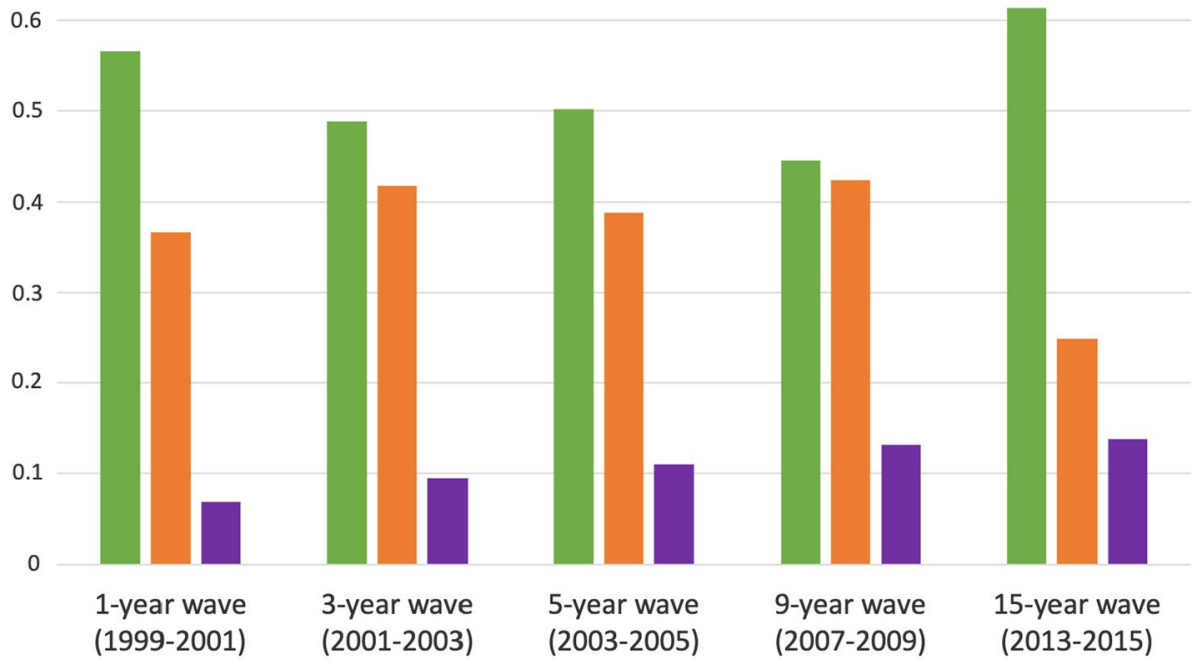

घimited Material Hardship घ Moderate Material Hardship घ Severe Material Hardship

Fig. 3 Prevalence of material hardship classes by wave

Table 3 Transition probabilities between latent classes over time

\begin{tabular}{|c|c|c|c|}
\hline & \multicolumn{3}{|c|}{ Material hardship class at 3-year wave } \\
\hline $\begin{array}{l}\text { Material hardship class at } \\
\text { 1-year wave }\end{array}$ & Limited & Moderate & Severe \\
\hline Limited & 0.818 & 0.172 & 0.01 \\
\hline Moderate & 0.106 & 0.823 & 0.071 \\
\hline Severe & 0.021 & 0.043 & 0.936 \\
\hline & \multicolumn{3}{|c|}{ Material hardship class at 5-year wave } \\
\hline $\begin{array}{l}\text { Material hardship class at } \\
\text { 3-year wave }\end{array}$ & Limited & Moderate & Severe \\
\hline Limited & 0.915 & 0.077 & 0.008 \\
\hline Moderate & 0.14 & 0.801 & 0.06 \\
\hline Severe & 0.028 & 0.09 & 0.881 \\
\hline & \multicolumn{3}{|c|}{ Material hardship class at 9-year wave } \\
\hline $\begin{array}{l}\text { Material hardship class at } \\
\text { 5-year wave }\end{array}$ & Limited & Moderate & Severe \\
\hline Limited & 0.811 & 0.189 & 0 \\
\hline Moderate & 0.048 & 0.831 & \\
\hline Severe & 0.094 & 0.062 & 0.844 \\
\hline & \multicolumn{3}{|c|}{ Material hardship class at 15 -year wave } \\
\hline $\begin{array}{l}\text { Material hardship class at } \\
\text { 9-year wave }\end{array}$ & Limited & Moderate & Severe \\
\hline Limited & 0.942 & 0.028 & 0.03 \\
\hline Moderate & 0.268 & 0.67 & 0.01 \\
\hline Severe & 0.179 & 0.054 & 0.766 \\
\hline
\end{tabular}

Waves correspond to years as follows: baseline, 1998-2000; 1-year wave, 1999-2001; 3-year wave, 2001-2003; 5-year wave, 2003-2005; 9-year wave, 2007-2009; 15-year wave, 2013-2015. Shading is provided for visual clarity only 


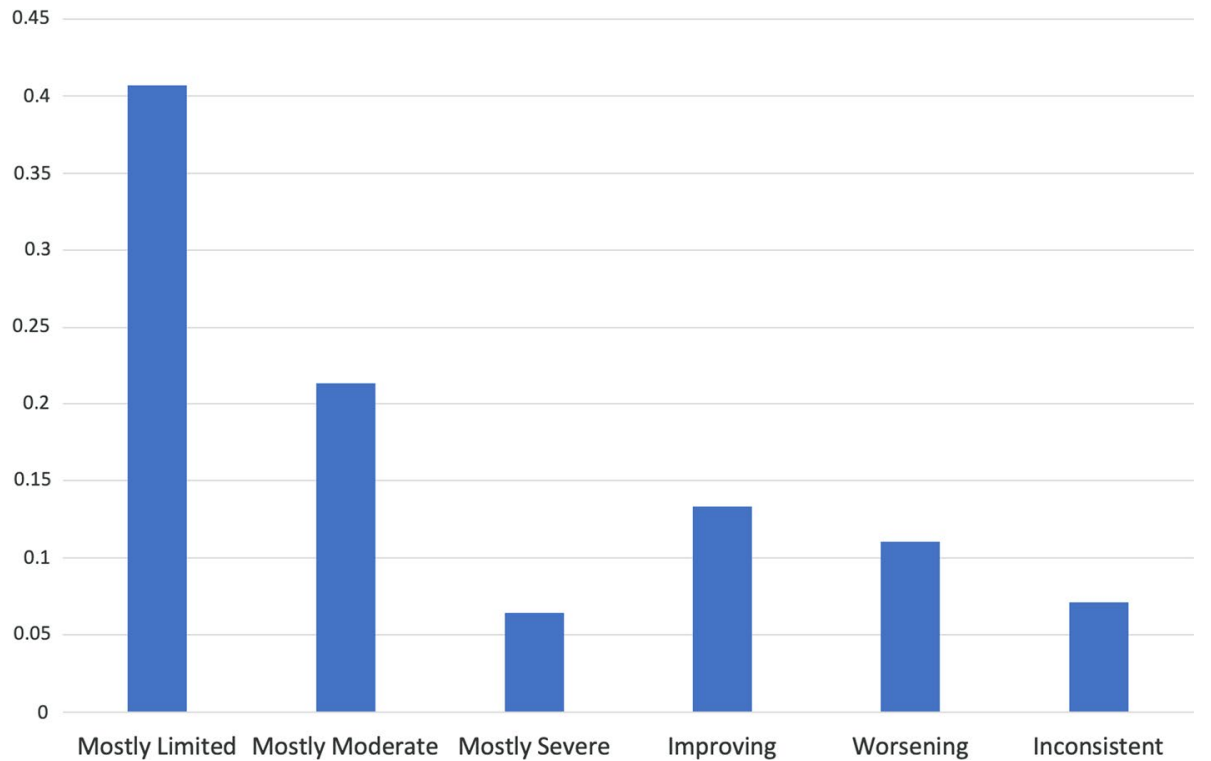

Fig. 4 Prevalence of material hardship patterns

derived from the most probable sequences of transitions between material hardship classes over time. Those six patterns were Mostly Limited, a pattern characterized by experiences of limited material hardship class at most (3 or more) time points; Mostly Moderate, a pattern characterized by primarily experiences of moderate material hardship class at most time points; Mostly Severe, a pattern characterized by experiences of severe material hardship class at most time points; Improving, a pattern characterized by a progression from more to less extreme experiences of material hardship class over time; Worsening, a pattern characterized by a progression from less to more extreme experiences of material hardship class over time; and Inconsistent, a pattern of irregular and infrequent combinations of material hardship class over time. The prevalence of each of the longitudinal patterns of material hardship is presented in Fig. 4.

The results presented in Fig. 4 indicate that a plurality of families experienced only limited hardship, but a similar portion of families experienced hardship that was consistently moderate to severe or which worsened over time. Because these analyses were exploratory, I conducted final, post-hoc descriptive analyses, presented in Figs. 5 and 6, which examined income poverty among families experiencing each longitudinal material hardship pattern.

Figure 5 captures proportions of families whose income was above the FPL in all five study waves, while Fig. 6 depicts proportions of families whose income was above the FPL in at least four of five study waves. Among those families in the mostly moderate and improving material hardship patterns, a quarter never experienced income poverty during the study period, and $43 \%$ and $46 \%$, respectively, had income above $100 \%$ FPL in at least four of five waves. Even among those families in the mostly severe and worsening material hardship patterns, income poverty was far from universal: $13 \%$ and $17 \%$, respectively, never experienced income poverty, and nearly a third in each pattern (30\% and 29\%) had income above $100 \%$ FPL in at least four of five waves. By contrast, in any given wave, about a quarter of families who experienced no hardship had income under 100\% FPL. 
0.6

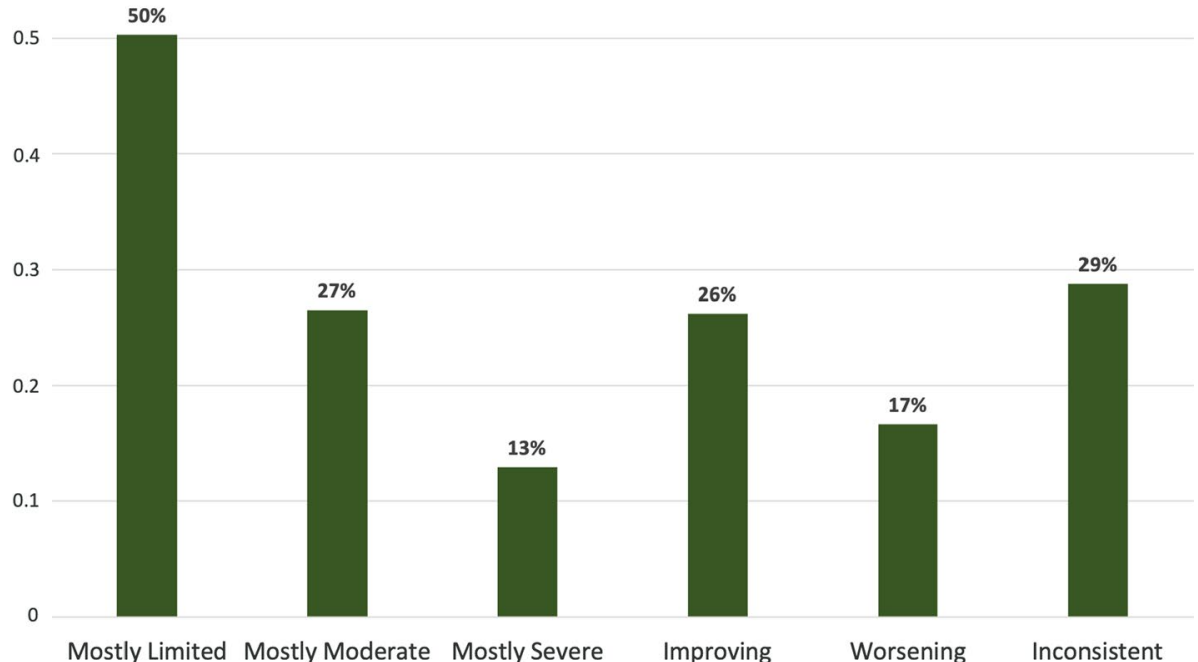

Fig. 5 Prevalence of income above $100 \%$ FPL in all 5 waves by material hardship pattern

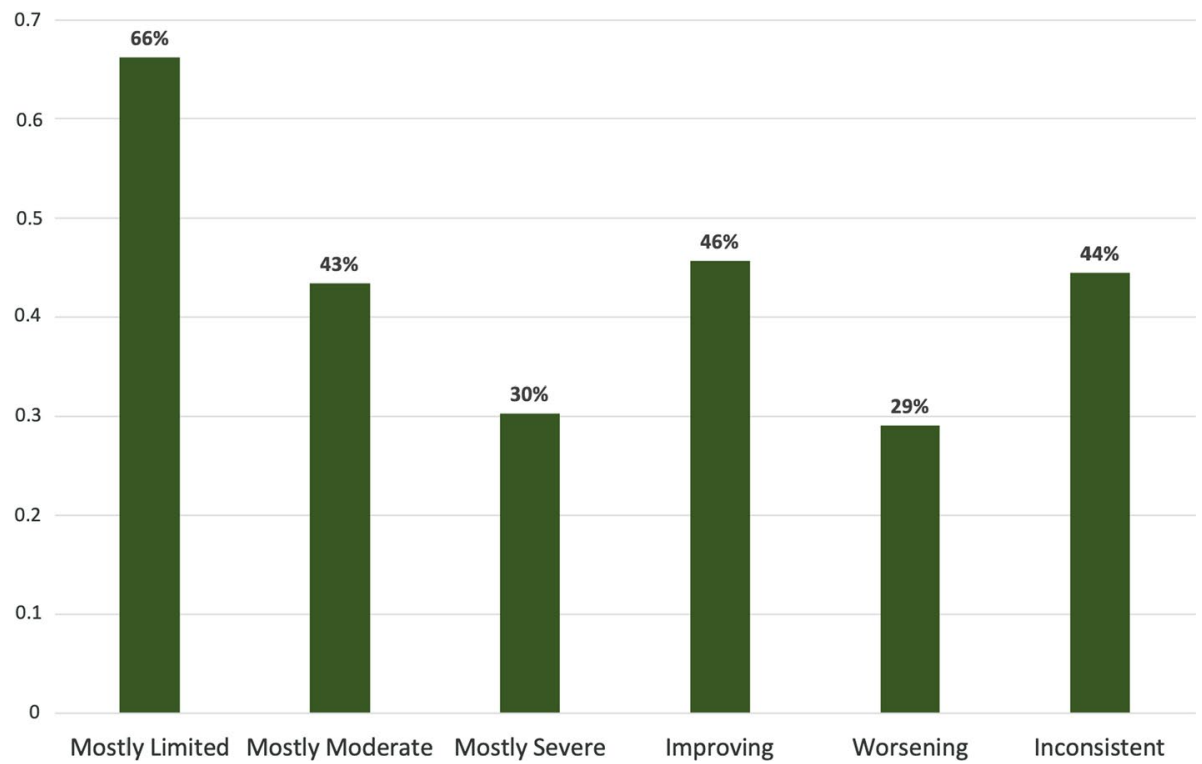

Fig. 6 Prevalence of income above $100 \%$ FPL in 4 or 5 waves by material hardship pattern 


\subsection{Correlates of Membership in Material Hardship Patterns}

Results of the multinomial logistic regression models examining social positioning correlates of the longitudinal patterns of material hardship outlined in Fig. 4 are presented in Table 4. Overall, the results of these models point to several factors which consistently predicted each of the more intense material hardship patterns as compared to the mostly limited pattern, with some important nuances. For instance, families with mothers who had some college education, compared to those with a college degree, consistently faced greater risk of all but the worsening material hardship pattern compared to the mostly limited pattern. Notably, this relationship was stronger and more consistent than the correlations between those with a high school degree or less than high school education as compared to those with a college degree, experiences which significantly differentiated only the mostly moderate from mostly limited pattern (risk ratio $(R R)=2.337)$. Families who rented their homes without government rental assistance (vs. owned) faced modest increased risk of mostly moderate $(\mathrm{RR}=1.316)$ and improving $(R R=1.348)$ patterns and marginally significant $(\mathrm{p}<.10)$ increased risk of mostly severe $(\mathrm{RR}=1.475)$ and worsening (1.354) patterns. Families in which mothers were cohabitating but not married to the focal child's father (vs. married) also consistently faced greater risk of each of the more intense material hardship patterns compared to mostly limited, as did families in which mothers met criteria for clinical depression and in which mothers had income just below and just above the poverty threshold.

Risk ratios for each of the more intense material hardship patterns related to incometo-poverty status were fairly modest, ranging from 1.492 to 1.791 , with two important exceptions. First, deep poverty (income $<50 \%$ FPL), versus high income (income $300 \%+\mathrm{FPL})$, was associated with a sizable increased risk $(\mathrm{RR}=2.172)$ for the worsening material hardship pattern, although deep poverty was not otherwise a strong predictor of pattern membership. Second, each category of lower income-to-poverty ratio from 50 to 99\% FPL through 200-299\% FPL (compared to 300\% + FPL) was associated with substantially higher risk of the mostly severe material hardship pattern compared to mostly limited (RRs from 2.028 to 2.255 ).

These results reflect a broader trend of notably larger risk ratios for the mostly severe material hardship pattern (vs. mostly limited) as compared to the other patterns. This trend held across those factors which were generally significant, including maternal education $(\mathrm{RR}=3.908)$, maternal relationship status $(\mathrm{RR}=2.825)$, and maternal depression $(\mathrm{RR}=5.669)$, and also extended to factors which were significant in predicting the mostly severe pattern but not other patterns. These included a strong protective effect for families in which the mother was Latinx (vs. white, non-Latinx; $R R=0.274$ ); notable increased risk among families receiving government rental assistance $(R R=2.958)$ or living in public housing $(\mathrm{RR}=2.888)$, compared to homeowners; increased risk for mothers raising more children $(\mathrm{RR}=1.203)$; and increased risk among mothers who had worked in the year prior to the focal child's birth $(R R=2.100)$. Additionally, while having lived with both of their own biological parents at age 15 was significantly protective against experiencing the mostly moderate $(R R=0.703)$ and increasing $(R R=0.634)$ material hardship patterns, and marginally protective $(\mathrm{p}<.10)$ against the worsening pattern $(R R=0.756)$, this factor was not significant in differentiating the mostly severe from mostly limited patterns.

Of note, maternal racial and ethnic group membership was not a consistent predictor of material hardship pattern. Families with Black, non-Latinx mothers (vs. white 


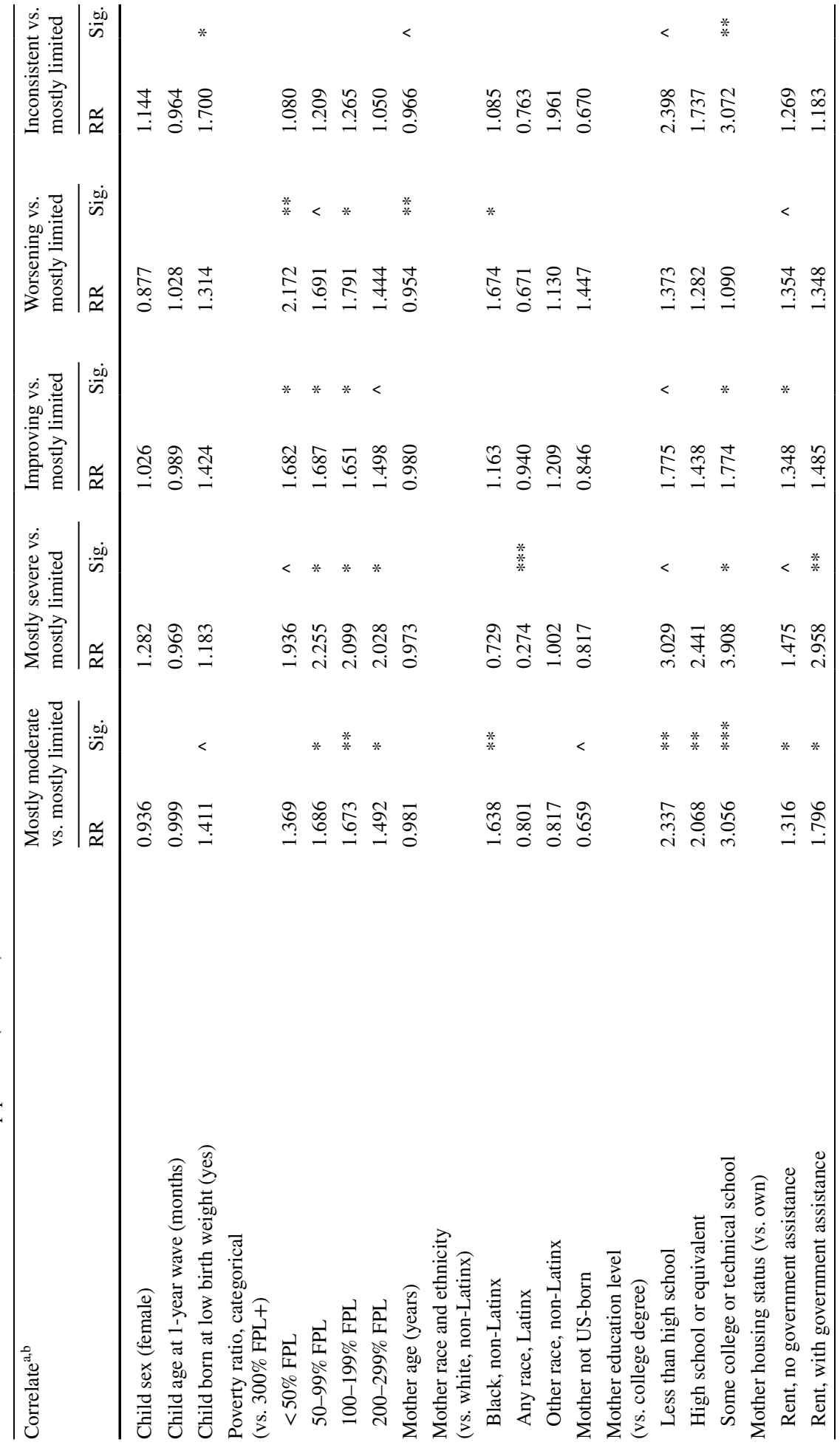




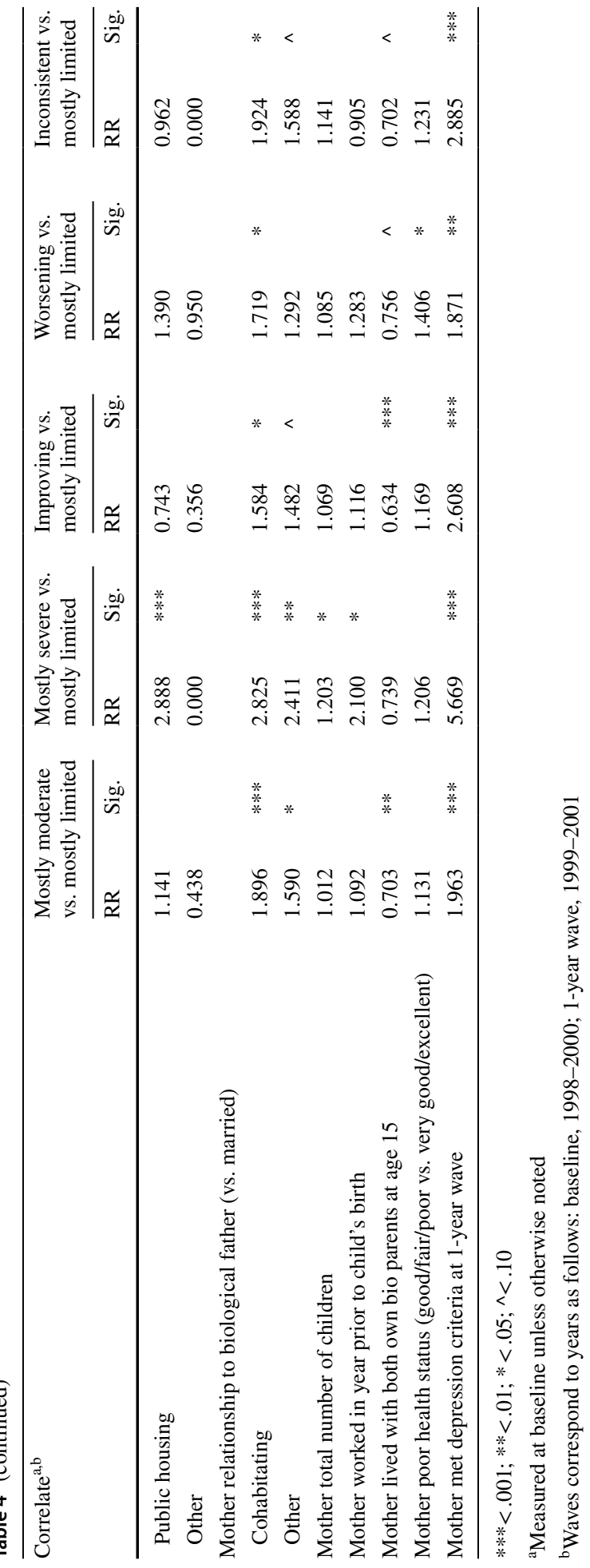


non-Latinx) faced higher risk of the mostly moderate $(\mathrm{RR}=1.638)$ and worsening $(\mathrm{RR}=1.674)$ material hardship patterns compared to mostly limited but did not face differences in risk for the mostly severe or improving patterns. While families with a Latinx mother experienced strong protection from the mostly severe material hardship pattern, this association did not hold for any other patterns.

\section{Discussion}

The empirical results identifying both classes and patterns of material hardship offer an additional, essential finding: material hardship is a widespread experience among US families. In this study, about $40-50 \%$ of families experienced moderate or severe material hardship in each wave, and $60 \%$ of families experienced moderate, severe, or worsening longitudinal material hardship patterns. The correlates of these experiences matter enormously to help us understand potential causes and points of intervention, but a central finding here is the common experience of complex and intense material hardship. Further, the study's findings of substantial experiences of material hardship suggest that, whatever measurement error may exist in the assessment of public assistance program participation impacts, the US. social welfare system is demonstrably not meeting the most basic needs of a notable proportion of families (Rodems \& Shaefer, 2020).

As the first longitudinal examination of material hardship, this study leveraged 15 years of data to identify new and conceptually meaningful patterns of material hardship. The six patterns which emerged describe families' experiences of stability in varying intensities of hardship (e.g., mostly limited, mostly moderate, and mostly severe material hardship) and of change over time in hardship intensity (e.g., improving, worsening, and inconsistent material hardship). Beyond identifying these patterns, the results demonstrated that there are consistent distinctions between patterns of limited to no material hardship and more intense patterns of hardship, particularly consistently severe hardship, suggesting that families may experience material hardship differently depending on their social positioning. Taken together, the findings of this study provide a novel and multifaceted conceptualization of deprivation and valuable evidence about differential impacts of social positioning characteristics on families' experiences of material hardship.

By investigating patterns of material hardship using an approach that incorporates substantively discrete domains of hardship, accounts for concurrent or intertwined experience of these domains, and considers longitudinal experiences of hardship, this study provides new and vital information about the complexity and prevalence of deprivation among US families.

Specifically, these novel findings indicate that over a nearly 15 -year period, three in five families in this sample consistently experienced more than limited hardship, and two in five experienced hardship that was steadily moderate or severe or that increased in intensity 
over time. Moreover, and underscoring findings from previous research that have pointed to income poverty and hardship as meaningfully distinct, post hoc descriptive analysis of these material hardship patterns demonstrated the divergence of families' experiences of longitudinal material hardship from their experiences of income poverty over the same period. Of particular note, while differences in income-to-poverty ratio were modestly correlated with experiences of some patterns of material hardship in the multinomial logistic regression models, these relationships were not universal nor on a clear gradient (that is, more income did not steadily decrease risk of hardship within or across material hardship patterns). These findings highlight the valuable new information that these multifaceted, longitudinal patterns of material hardship can offer about family deprivation. Without understanding material hardship in complex ways like the conceptualization articulated here, we have only a limited comprehension of the unmet basic needs many families face.

The identification of longitudinal material hardship patterns is entirely novel; however, some of the multinomial logistic regression findings are consistent with prior work and provide important evidence vital to understanding structural inequities. For instance, results demonstrate the detrimental association between mothers' attainment of some college education and families' economic wellbeing, consistent with prior research (Groves et al., 2018; Heflin, 2017; Pilkauskas et al., 2012; Winston et al., 2017). This finding may reflect the negative impact of higher education debt without the economic benefit of a college degree. It is also possible that parents who attend but do not complete college face other, unmeasured economic detriments which contribute to both incomplete college education and more intense material hardship patterns.

This study found higher risk for some material hardship patterns among families with Black, non-Latinx mothers, results which reflect the well-established negative impacts of anti-Black racism, including exposure to mass incarceration and discrimination in education, employment, and housing, all of which may lead to decreased family economic wellbeing (Krieger, 2000). Prior research demonstrates significant associations between paternal incarceration and material hardship (Schwartz-Soicher et al., 2011), and broader evidence makes clear the extensive, deleterious effects of racism on economic wellbeing (Charles, 2003; Krieger, 2000; Nazroo, 2003), including greater rates of food and housing hardship among Black adults compared to white adults (Finegold \& Wherry, 2004; Heflin, 2017). Importantly, this study also finds that families with Latinx mothers are less likely to experience consistently severe material hardship. This finding may reflect differences in experiences of material hardship related to cultural norms around resource sharing and to citizenship and legal status (Blank \& Torrecilha, 1998; Kalil \& Chen, 2008). Whatever the explanation, these results suggest the need for further, clarifying work examining the underlying structural mechanisms, flagged by these social positioning characteristics, which operate to increase and decrease the likelihood of more intense material hardship. Such additional evidence could contribute to improved policy design and program 
targeting to meet group-specific needs and to formulate effective interventions to prevent experiences of material hardship.

\section{Limitations}

The FFCWS dataset presents two important limitations for the present study. First, the study cohort can be weighted to be representative of large US cities but not of the country as a whole. This limited generalizability is intentional and is accompanied by important strengths. Namely, the dataset includes a large sample representative of marginalized and often difficult to reach urban families. An additional limitation to the dataset's design is the variation in between-wave periods, ranging from 1 to 6 years. Most notably, the 6-year period between the waves at which the focal child was about 9 years old and about 15 years old represents a sizable time during which some families likely experienced changes in material hardship for which the present study cannot account. Nonetheless, the FFCWS dataset remains the sole source of repeated, consistent measures of material hardship (with the exception of the 2008 SIPP which measured hardship at two waves). Those measures, accompanied by the extensive family social positioning information included in the dataset, allowed for the novel longitudinal analyses in this study. Second, it is important to note that the 9-year wave of the FFCWS data used in this study was collected around the time of the Great Recession (2007-2009). This unusually volatile economic period likely impacted families' experiences of material hardship (Pilkauskas et al., 2012), and it is particularly important that future research examine longitudinal measures of material hardship in other time periods, to assess whether similar patterns emerge. In turn, this suggests the importance of future, systematic data collection that includes repeated measures of material hardship, as no data source other than the FFCWS has consistently collected such measures to date.

Finally, while collecting data on material hardship in more surveys is critical, the limitations of current material hardship measures, including some of those in the FFCWS data, warrant consideration prior to their expansion. For instance, the only consistent question on food hardship in the FFCWS pertains to accessing free food resources, a measure of food need but not one that is consistent with the well-established US Department of Agriculture (USDA) measure of food insecurity (Heflin \& Olson, 2017). While the measure examined in this study captures one form of food hardship, the robust literature on food insecurity and its deleterious consequences suggests the empirical and clinical value of measuring food hardship in terms of food insecurity. While the full USDA food insecurity measure may not be a viable addition to all surveys, an abbreviated form of that measure has also been tested and validated (Hager et al., 2010), and could be incorporated into future material hardship data collection. 


\section{Implications}

As the strengths and limitations of the FFCWS dataset suggest, one of the central research implications of this study is the importance of gathering consistent, high-quality, repeated material hardship measures, a key social indicator. The FFCWS will continue to be a leading source for such data, and it is also essential that other research and government surveys begin or expand their collection of material hardship data. For instance, the US Census Bureau previously collected nationally representative material hardship data via the SIPP, but these measures were previously cross-sectional, collected once per every 4-year panel, and are now repeated annually but including only a subset of material hardship types (National Academies of Sciences, Engineering, and Medicine, 2018). The US Census Bureau could expand its collection of material hardship data by including the full battery of material hardship questions in each wave of the SIPP and by incorporating those measures into the Current Population Survey Annual Social and Economic Supplement (CPSASEC), providing annual national data on material hardship (Thomas, 2020).

While additional data sources are critical to the ongoing study of material hardship, this study also suggests important conceptual directions for future research. For instance, the present findings focus on movement between and stability in given experiences of material hardship, and these transitions are likely linked to other changes, particularly short-term shocks which change the economic and social conditions families face. Prior research suggests that such household shocks - lost employment, changes in household make up, health incidentsmay predict transitions in material hardship experience (e.g., Heflin, 2016; Heflin \& Butler, 2013). Future work building on this study's longitudinal findings should examine such potential triggers of transitions in hardship, in addition to those external factors such as the macroeconomic context of the Great Recession, noted in the Limitations section, and similar consequences of the pandemic-related recession and subsequent policy responses. Finally, the FFCWS data offer a particularly rich opportunity to examine life course differences in transitions and trajectories of material hardship experience. Future research can assess possible differences in those factors shaping families' experiences of hardship at key stages of child and family development.

Together, the conceptual and empirical findings of this study have a number of policy implications. For instance, results of this study suggest that, in relying on income poverty, US policymakers are missing experiences of deprivation in terms of basic need which affect huge proportions of US families. Current material hardship measures, including the classes and patterns identified in this study, do not lend themselves to use as measures of individual family needs in the implementation of social welfare policy, both because there is not a consensus as to which hardship measure(s) and possible cutoffs could indicate need and because current metrics rely on numerous data points combined with methods more complex and onerous to implement in practice than do simple income measures. Instead, present material hardship measures have the potential to inform our ongoing assessments of community, state, and national-level needs by clarifying the extent and intensity of unmet basic needs in the US, separate but complementary to ongoing measurement of income poverty. 
This study's descriptive findings indicate that many families with moderate but non-poverty income still face material hardship, yet anti-hardship policies in the US, like food and housing assistance, are targeted to income-poor families. A potential incremental response to this misalignment could be to notably increase income eligibility cutoffs for core US public assistance programs. The demonstrated presence of material hardship among families with incomes up to $400 \%$ of FPL (e.g., see Karpman et al., 2018b; Rodems \& Shaefer, 2020) suggest that raising public assistance income eligibility levels to that range would be a beneficial and administratively straightforward, although undoubtedly expensive, response to the pervasiveness of material hardship among low- and moderate-income families. A more aspirational policy response would account for the important differences between income poverty and material hardship and might couple more generous income cut-offs with new policy mechanisms keyed to some of the essential experiences of material hardship. For instance, a new program could provide access to immediate cash benefits to prevent essential bill-paying hardship that might precipitate entrance into a more intense material hardship class or pattern. Other policy approaches might include guarantees of in-kind supports to meet basic needs, such as significantly expanded housing assistance, food assistance, and universal health care policies. Temporary versions of some such policy responses have been implemented in 2021 through the American Rescue Plan Act, including expanded food assistance and Child Tax Credit benefits, which are expected to reduce child poverty significantly (Parolin et al., 2021). The Biden administration's proposal to extend such benefits permanently could substantially improve economic wellbeing for US families: estimates suggest that that maintaining such anti-hardship and anti-poverty policies could cut child poverty rates by nearly half (Collyer et al., 2021).

\section{Conclusion}

This study expands our understanding of deprivation, considering need in all of its realistic complexity, as a multifaceted, time-varying experience. This conceptual work demonstrates the viability and utility of considering alternative measures of social phenomena like poverty, while the empirical contributions of this study improve our understanding of economic wellbeing, extending the burgeoning material hardship literature base to include evidence on longitudinal experiences of hardship. These findings have implications for our understanding, measurement, and responses to the essential social indicator of material hardship.

\section{Appendix 1}

See Table 5. 
Table 5 Difference in analytic and excluded sample descriptive statistics, unweighted

\begin{tabular}{|c|c|c|c|}
\hline \multirow[t]{2}{*}{ Characteristic $c^{\mathrm{a}, \mathrm{b}}$} & $\begin{array}{l}\text { Analytic sam- } \\
\text { ple }(\mathrm{n}=2772)\end{array}$ & $\begin{array}{l}\text { Excluded sam- } \\
\text { ple }(n=2126)\end{array}$ & $\begin{array}{l}\text { Difference } \\
\text { between } \\
\text { samples }\end{array}$ \\
\hline & Proportion & Proportion & Sig. \\
\hline Child sex (male) & 0.518 & 0.527 & \\
\hline Child age at 1 -year wave (months) & 14.918 & 15.195 & $*$ \\
\hline Child born at low birth weight (yes) & 0.093 & 0.113 & $*$ \\
\hline Poverty ratio, continuous & 2.294 & 2.009 & $* * *$ \\
\hline \multicolumn{3}{|l|}{ Poverty ratio, categorical } & $* * *$ \\
\hline$<50 \%$ FPL & 0.168 & 0.218 & \\
\hline $50-99 \%$ FPL & 0.166 & 0.181 & \\
\hline 100-199\% FPL & 0.261 & 0.253 & \\
\hline 200-299\% FPL & 0.160 & 0.148 & \\
\hline $300 \%+\mathrm{FPL}$ & 0.245 & 0.200 & \\
\hline Mother age (years) & 25.209 & 25.363 & \\
\hline \multicolumn{3}{|l|}{ Mother race and ethnicity } & $* * *$ \\
\hline White, non-Latinx & 0.233 & 0.182 & \\
\hline Black, non-Latinx & 0.501 & 0.443 & \\
\hline Any race, Latinx & 0.232 & 0.328 & \\
\hline Other race, non-Latinx & 0.034 & 0.047 & \\
\hline Mother not US-born & 0.122 & 0.233 & $* * *$ \\
\hline \multicolumn{3}{|l|}{ Mother education level } & $* * *$ \\
\hline Less than high school & 0.300 & 0.409 & \\
\hline High school or equivalent & 0.320 & 0.280 & \\
\hline Some college or technical school & 0.261 & 0.219 & \\
\hline College or advanced degree & 0.119 & 0.092 & \\
\hline \multicolumn{3}{|l|}{ Mother housing status } & $* * *$ \\
\hline Own & 0.371 & 0.297 & \\
\hline Rent, no government assistance & 0.456 & 0.536 & \\
\hline Rent, with government assistance & 0.061 & 0.066 & \\
\hline Public housing & 0.108 & 0.098 & \\
\hline Other & 0.005 & 0.003 & \\
\hline \multicolumn{4}{|l|}{ Mother relationship to biological father } \\
\hline Married & 0.252 & 0.230 & \\
\hline Cohabitating & 0.355 & 0.376 & \\
\hline Other & 0.393 & 0.395 & \\
\hline Mother total number of children & 2.100 & 2.260 & $* * *$ \\
\hline Mother did not work in year prior to child's birth & 0.154 & 0.223 & $* * *$ \\
\hline Mother did not live with both own bio parents at age 15 & 0.581 & 0.550 & $*$ \\
\hline $\begin{array}{l}\text { Mother poor health status (good/fair/poor vs. very good/ } \\
\text { excellent) }\end{array}$ & 0.325 & 0.371 & $* * *$ \\
\hline Mother met depression criteria at 1-year wave & 0.157 & 0.151 & \\
\hline
\end{tabular}

$* * *<.001 ; * *<.01 ; *<.05$

${ }^{a}$ Measured at baseline unless otherwise noted

${ }^{b}$ Waves correspond to years as follows: baseline, 1998-2000; 1-year wave, 1999-2001 


\section{Appendix 2}

See Tables 6 and 7.

Table 6 LCA model fit comparisons

\begin{tabular}{lc}
\hline Number of classes & BIC \\
\hline Time 1 (1-year wave) & \\
3 & $\mathbf{9 9 7 6 . 9 7 4}$ \\
4 & $10,016.85$ \\
5 & $10,060.703$ \\
Time 2 (3-year wave) & \\
3 & $\mathbf{1 0 , 6 0 9 . 9 7 1}$ \\
4 & $10,636.867$ \\
5 & $10,680.938$ \\
Time 3 (5-year wave) & \\
3 & $\mathbf{1 0 , 2 3 4 . 0 4 9}$ \\
4 & $10,265.844$ \\
5 & $10,310.14$ \\
Time 4 (9-year wave) & \\
3 & $\mathbf{1 0 , 9 2 3 . 0 4 4}$ \\
4 & $10,957.667$ \\
5 & $11,002.471$ \\
Time 5 (15-year wave) & \\
3 & $\mathbf{9 5 9 1 . 9 4 2}$ \\
4 & 9626.37 \\
5 & 9667.965 \\
\hline
\end{tabular}

Bold indicates best fitting model

Table 7 Measurement invariance model comparison

\begin{tabular}{lll}
\hline Model & Measurement invariance & BIC \\
\hline 3-Solution & Yes & $\mathbf{4 8 , 6 3 1 . 2 1 3}$ \\
3-Solution & No & $48,767.408$ \\
\hline
\end{tabular}

Bold indicates best fitting model 
Author Contributions Dr. Thomas is the sole author.

Funding This research was supported in part by a dissertation grant from the Horowitz Foundation for Social Policy. The content is solely the responsibility of the author and does not necessarily represent the views of the Horowitz Foundation for Social Policy. This research was supported in part by the Eunice Kennedy Shriver National Institute of Child Health and Human Development (NICHD) of the National Institutes of Health under a training workshop grant awarded to Columbia Population Research Center at Columbia University, R25HD074544, and under award numbers R01HD36916, R01HD39135, and R01HD40421, as well as a consortium of private foundations. The content is solely the responsibility of the author and does not necessarily represent the official views of the NICHD nor the National Institutes of Health.

Data Availability The data are publicly available to registered users through the Princeton University Office of Population Research data archive, accessible here: https://opr.princeton.edu/archive/restricted/Default. aspx.

Code Availability Software code may be available upon direct request to the author.

\section{Declarations}

Conflict of interest The author has no conflicts of interest to declare.

Ethical Approval This study was exempt from IRB approval.

\section{Consent to Participate N/A.}

\section{Consent for Publication N/A.}

Open Access This article is licensed under a Creative Commons Attribution 4.0 International License, which permits use, sharing, adaptation, distribution and reproduction in any medium or format, as long as you give appropriate credit to the original author(s) and the source, provide a link to the Creative Commons licence, and indicate if changes were made. The images or other third party material in this article are included in the article's Creative Commons licence, unless indicated otherwise in a credit line to the material. If material is not included in the article's Creative Commons licence and your intended use is not permitted by statutory regulation or exceeds the permitted use, you will need to obtain permission directly from the copyright holder. To view a copy of this licence, visit http://creativecommons.org/licenses/by/4.0/.

\section{References}

Beverly, S. G. (2001). Material hardship in the United States: Evidence from the Survey of Income and Program Participation. Social Work Research, 25(3), 143-151.

Blank, S., \& Torrecilha, R. S. (1998). Understanding the living arrangements of Latino immigrants: A life course approach. International Migration Review, 32(1), 3-19. https://doi.org/10.2307/2547558

Bradshaw, J., \& Finch, N. (2003). Overlaps in dimensions of poverty. Journal of Social Policy, 32(4), 513525. https://doi.org/10.1017/S004727940300713X

Brooks-Gunn, J., \& Duncan, G. (1997). The effects of poverty on children. The Future of Children, 7(2), 55-71. https://doi.org/10.2307/1602387

Carle, A. C., Bauman, K. J., \& Short, K. (2009). Assessing the measurement and structure of material hardship in the United States. Social Indicators Research, 92(1), 35-51. https://doi.org/10.1007/ s11205-008-9287-7

Carlson, B. L. (2008). Fragile families \& child wellbeing study: Methodology for constructing mother, father, and couple weights for core telephone public survey data waves 1-4. Mathematica Policy Research.

Center on Poverty and Social Policy. (2019). Robin Hood Poverty Tracker. Columbia University. https:// www.povertycenter.columbia.edu/poverty-tracker-data 
Charles, C. Z. (2003). The dynamics of racial residential segregation. Annual Review of Sociology, 29(1), 167-207. https://doi.org/10.1146/annurev.soc.29.010202.100002

Chaudry, A., \& Wimer, C. (2016). Poverty is not just an indicator: The relationship between income, poverty, and child well-being. Academic Pediatrics, 16(3), S23-S29. https://doi.org/10.1016/j.acap.2015. 12.010

Collins, L. M., \& Lanza, S. T. (2010). Latent class and latent transition analysis: With applications in the social, behavioral, and health sciences. Wiley.

Collyer, S., Curran, M. A., Hartley, R. P., Parolin, Z., \& Wimer, C. (2021). The potential poverty reduction effect of the American families plan. Center on Poverty and Social Policy, Columbia University. https:// static1.squarespace.com/static/610831a16c95260dbd68934a/t/6116a2c1cb768c23269b1add/16288 73410837/Poverty-Reduction-Analysis-American-Families-Plan-CPSP-2021.pdf.

Dhongde, S., \& Haveman, R. (2015). Multi-dimensional poverty index: An application to the United States. Retrieved from https://www.irp.wisc.edu/publications/dps/pdfs/dp142715.pdf

Duncan, G., Brooks-Gunn, J., \& Klebanov, P. K. (1994). Economic deprivation and early childhood development. Child Development, 65(2), 296-318. https://doi.org/10.2307/1131385

Finegold, K., \& Wherry, L. (2004). Race, ethnicity, and economic well-being. Retrieved from http://webar chive.urban.org/UploadedPDF/310968_snapshots3_no19.pdf

Gershoff, E. T., Aber, J. L., Raver, C. C., \& Clare, M. (2007). Income is not enough: Incorporating material hardship into models of income associations with parenting and child development. Child Development, 78(1), 70-95. https://doi.org/10.1111/j.1467-8624.2007.00986.x

Groves, L., Winston, P., \& Mellgren, L. (2018). Cross-domain instability in families with some college education. Retrieved from https://aspe.hhs.gov/system/files/pdf/259266/FamilyInstability_SomeColleg eBrief.pdf

Hager, E. R., Quigg, A. M., Black, M. M., Coleman, S. M., Heeren, T., Rose-Jacobs, R., Cook, J. T., de Cuba, S. A. E., Casey, P. H., Chilton, M., Cutts, D. B., Meyers, A. F., \& Frank, D. A. (2010). Development and validity of a 2-item screen to identify families at risk for food insecurity. Pediatrics, 126(1), e26-e32. https://doi.org/10.1542/peds.2009-3146

Hardy, B. (2014). Childhood income volatility and adult outcomes. Demography, 51(5), 1641-1665. https:// doi.org/10.1007/s13524-014-0329-2

Heflin, C. M. (2006). Dynamics of material hardship in the Women's Employment Study. Social Service Review, 80(3), 377-397. https://doi.org/10.1086/505289

Heflin, C. M. (2016). Family instability and material hardship: Results from the 2008 Survey of Income and Program Participation. Journal of Family and Economic Issues, 37(3), 359-372. https://doi.org/10. 1007/s10834-016-9503-6

Heflin, C. M. (2017). The role of social positioning in observed patterns of material hardship: New evidence from the 2008 Survey of Income and Program Participation. Social Problems. https://doi.org/10.1093/ socpro/spw041

Heflin, C. M., \& Butler, J. S. (2013). Why do women enter and exit from material hardship? Journal of Family Issues, 34(5), 631-660. https://doi.org/10.1177/0192513X12442822.

Heflin, C. M., \& Iceland, J. (2009). Poverty, material hardship, and depression. Social Science Quarterly, 90(5), 1051-1071. https://doi.org/10.1111/j.1540-6237.2009.00645.x

Heflin, C. M., \& Olson, K. (2017). Unpacking an anomaly: Analyzing the 2005-2012 current population survey to understand why many emergency food assistance users report being food secure. Journal of Hunger \& Environmental Nutrition, 12(1), 64-76. https://doi.org/10.1080/19320248.2016.1157548

Heflin, C. M., Sandberg, J., \& Rafail, P. (2009). The structure of material hardship in U.S. households: An examination of the coherence behind common measures of well-being. Social Problems, 56(4), 746-764. https://doi.org/10.1525/sp.2009.56.4.746

Kalil, A., \& Chen, J.-H. (2008). Mothers' citizenship status and household food insecurity among lowincome children of immigrants. New Directions for Child and Adolescent Development, 121, 43-62. https://doi.org/10.1002/cd.222

Karpman, M., Zuckerman, S., \& Gonzalez, D. (2018b). Material hardship among nonelderly adults and their families in 2017: Implications for the safety net. Retrieved from https://www.urban.org/sites/default/ files/publication/98918/material_hardship_among_nonelderly_adults_and_their_families_in_2017.pdf

Karpman, M., Gonzalez, D., Zuckerman, S., \& Adams, G. (2018a). What explains the widespread material hardship among low-income families with children? Retrieved from https://www.urban.org/sites/defau 1t/files/publication/99521/what_explains_the_widespread_material_hardship_among_low-income_ families_with_children_0.pdf

Krieger, N. (2000). Refiguring "race": Epidemiology, racialized biology, and biological expressions of race relations. International Journal of Health Services, 30(1), 211-216. https://doi.org/10.2190/ 672J-1PPF-K6QT-9N7U 
Lanza, S. T., \& Collins, L. M. (2008). A new SAS procedure for latent transition analysis: Transitions in dating and sexual risk behavior. Developmental Psychology, 44(2), 446-456. https://doi.org/10.1037/ 0012-1649.44.2.446.A

Lanza, S. T., \& Rhoades, B. L. (2013). Latent class analysis: An alternative perspective on subgroup analysis in prevention and treatment. Prevention Science, 14(2), 157-168. https://doi.org/10.1007/ s11121-011-0201-1

Mayer, S. E., \& Jencks, C. (1989). Poverty and the distribution of material hardship. The Journal of Human Resources, 24(1), 88-114. https://doi.org/10.2307/145934

McCarthy, B. B., Carter, A., Jansson, M., \& Benoit, C. (2016). Material hardship shows a clearer picture of mental health among low-wage workers. Retrieved from https://poverty.ucdavis.edu/sites/main/files/ file-attachments/cpr-mccarthy_carter_material_hardship_brief_0.pdf

McKernan, S.-M., Ratcliffe, C., \& Iceland, J. (2018). The effect of the US safety net on material hardship over the past quarter-century. Retrieved from https://www.urban.org/sites/default/files/publication/ 99295/the_effect_of_the_us_safety_net_on_material_hardship_0.pdf

McLanahan, S. S., Garfinkel, I., \& Waller, M. R. (1999). The fragile families and child well-being study. Retrieved from https://www.ppic.org/content/pubs/op/OP_1199MWOP.pdf

Muthén, L. K., \& Muthén, B. O. (2019). Mplus, version 8.4. Muthén \& Muthén.

National Academies of Sciences, Engineering, and Medicine (2018). Adequacy of the content of the 2014 SIPP. In The 2014 redesign of the survey of income and program participation: An assessment ( $\mathrm{p}$. 24864). The National Academies Press. https://doi.org/10.17226/24864

Nazroo, J. Y. (2003). The structuring of ethnic inequalities in health: Economic position, racial discrimination, and racism. American Journal of Public Health, 93(2), 277-284. https://doi.org/10.2105/AJPH. 93.2.277

Neckerman, K. M., Garfinkel, I., Teitler, J. O., Waldfogel, J., \& Wimer, C. (2016). Beyond income poverty: Measuring disadvantage in terms of material hardship and health. Academic Pediatrics, 16(3), S52S59. https://doi.org/10.1016/j.acap.2016.01.015

Nepomnyaschy, L., \& Garfinkel, I. (2011). Fathers' involvement with their nonresident children and material hardship. The Social Service Review, 85(1), 3-38. https://doi.org/10.1086/658394

Nicoletti, C., Peracchi, F., \& Foliano, F. (2011). Estimating income poverty in the presence of missing data and measurement error. Journal of Business \& Economic Statistics, 29(1), 61-72. https://doi.org/10. 1198/jbes.2010.07185

Nylund, K. L. (2007). Latent transition analysis: Modeling extensions and an application to peer victimization. University of California Los Angeles.

Ouellette, T., Burstein, N., Long, D., \& Beecroft, E. (2004). Measures of material hardship: Final report. Retrieved from https://aspe.hhs.gov/system/files/pdf/73366/report.pdf

Parolin, Z., Collyer, S., Curran, M. A., \& Wimer, C. (2021). The potential poverty reduction effect of the American rescue plan. Center on Poverty and Social Policy, Columbia University. https://www.pover tycenter.columbia.edu/news-internal/2021/presidential-policy/biden-economic-relief-proposal-pover ty-impact

Payton Scally, C., \& Gonzalez, D. (2018). Homeowner and renter experiences of material hardship: Implications for the safety net. Retrieved from https://www.urban.org/sites/default/files/publication/99271/ homeowner_and_renter_experiences_of_material_hardship_implications_for_the_safety_net_4.pdf

Pilkauskas, N. V., Currie, J. M., \& Garfinkel, I. (2012). The Great Recession, public transfers, and material hardship. Social Service Review, 86(3), 401-427. https://doi.org/10.1086/667993

Princeton University. (2017). Data and documentation: Year 15. Retrieved December 31, 2017, from https:// fragilefamilies.princeton.edu/documentation/year15

Ratcliffe, C., \& Mckernan, S.-M. (2010). Childhood poverty persistence: Facts and consequences. Retrieved from https://www.urban.org/sites/default/files/publication/32926/412126-childhood-poverty-persi stence-facts-and-consequences.pdf

Reichman, N. E., Teitler, J. O., Garfinkel, I., \& McLanahan, S. S. (2001). Fragile families: Sample and design. Children and Youth Services Review, 23(4-5), 303-326.

Rodems, R., \& Shaefer, H. L. (2020). Many of the kids are not alright: Material hardship among children in the United States. Children and Youth Services Review, 112, 104767. https://doi.org/10.1016/j.child youth.2020.104767

Ryoo, J. H., Wang, C., Swearer, S. M., Hull, M., \& Shi, D. (2018). Longitudinal model building using latent transition analysis: An example using school bullying data. Frontiers in Psychology. https://doi.org/10. 3389/fpsyg.2018.00675

Schenck-Fontaine, A., \& Panico, L. (2019). Many kinds of poverty: Three dimensions of economic hardship, their combinations, and children's behavior problems. Demography, 56(6), 2279-2305. https:// doi.org/10.1007/s13524-019-00833-y. 
Schuler, M. S., Leoutsakos, J. M. S., \& Stuart, E. A. (2014). Addressing confounding when estimating the effects of latent classes on a distal outcome. Health Services and Outcomes Research Methodology, 14(4), 232-254. https://doi.org/10.1007/s10742-014-0122-0

Schwartz-Soicher, O., Geller, A., \& Garfinkel, I. (2011). The effect of paternal incarceration on material hardship. Social Service Review, 85(3), 447-473. https://doi.org/10.1086/661925

Shaefer, H. L., \& Gutierrez, I. A. (2013). The Supplemental Nutrition Assistance Program and material hardships among low-income households with children. Social Service Review, 87(4), 753-779. https://doi.org/10.1086/673999

Short, K. S. (2005). Material and financial hardship and income-based poverty measures in the USA. Journal of Social Policy, 34(1), 21-38. https://doi.org/10.1017/S0047279404008244

Stavseth, M. R., Clausen, T., \& Røislien, J. (2019). How handling missing data may impact conclusions: A comparison of six different imputation methods for categorical questionnaire data. SAGE Open Medicine, 7, 1-12. https://doi.org/10.1177/2050312118822912

Stone, S. I., \& Rose, R. A. (2011). Social work research and endogeneity bias. Journal of the Society for Social Work and Research, 2(2), 54-75. https://doi.org/10.5243/jsswr.2011.3

Sullivan, J. X., Turner, L., \& Danziger, S. (2008). The relationship between income and material hardship. Journal of Policy Analysis and Management, 27(1), 63-81. https://doi.org/10.1002/pam.20307

Survey Research Center, Institute for Social Research, University of Michigan. (2021). Panel study of income dynamics: Documentation. https://psidonline.isr.umich.edu/Guide/default.aspx

Thomas, M. M. C. (2020). Measuring material hardship is critical for capturing economic need in US Census Bureau data. Society for Social Work and Research. https://secure.sswr.org/wp-content/uploads/ 2020/08/1.-Thomas.pdf

Tolman, R. M., Danziger, S. H., Siefert, K., Danziger, S. K., Corcoran, M. E., \& Seefeldt, K. S. (2018). The women's employment study, genesee county, Michigan, 1997-2004. Inter-University Consortium for Political and Social Research. https://doi.org/10.3886/ICPSR37077.v1.

Weller, B. E., Bowen, N. K., \& Faubert, S. J. (2020). Latent class analysis: a guide to best practice. Journal of Black Psychology, 46(4), 287-311. https://doi.org/10.1177/0095798420930932

White, I. R., \& Carlin, J. B. (2010). Bias and efficiency of multiple imputation compared with completecase analysis for missing covariate values. Statistics in Medicine, 29(28), 2920-2931. https://doi.org/ $10.1002 / \operatorname{sim} .3944$

Wimer, C., Garfinkel, I., Gelblum, M., Lasala, N., Philips, S., Si, Y., Teitler, J., Waldfogel, J. (2014). Poverty tracker-Monitoring poverty and well-being in NYC, report 1 . Retrieved from https://robinhoodo rg-production.s3.amazonaws.com/uploads/2019/12/RH_PovertyTracker_Spring14.pdf

Winston, P., Groves, L., \& Mellgren, L. (2017). Exploring cross-domain instability in families with children. Retrieved from https://aspe.hhs.gov/pdf-report/exploring-cross-domain-instability-families-child ren

Wu, C. F., \& Eamon, M. K. (2010). Does receipt of public benefits reduce material hardship in low-income families with children? Children and Youth Services Review, 32(10), 1262-1270. https://doi.org/10. 1016/j.childyouth.2010.04.017

Yoo, J. P., Slack, K. S., \& Holl, J. L. (2009). Material hardship and the physical health of school-aged children in low-income households. American Journal of Public Health, 99(5), 829-836. https://doi.org/ 10.2105/AJPH.2007.119776

Zilanawala, A., \& Pilkauskas, N. V. (2012). Material hardship and child socioemotional behaviors: Differences by types of hardship, timing, and duration. Children and Youth Services Review, 34(4), 814-825. https://doi.org/10.1016/j.childyouth.2012.01.008

Publisher's Note Springer Nature remains neutral with regard to jurisdictional claims in published maps and institutional affiliations. 